\title{
Modeling adsorption equilibria of xylene isomers in a microporous metal-organic framework
}

\author{
Patrick S. Bárcia ${ }^{\mathrm{a}, \mathrm{c}}$, Macro P.M. Nicolau ${ }^{\mathrm{a}}$, Jose M. Gallegos ${ }^{\mathrm{b}}$, Banglin Chen ${ }^{\mathrm{b}}$, Alírio E. Rodrigues ${ }^{\mathrm{c}, *}$, \\ José A.C. Silva ${ }^{\mathrm{a}, *}$ \\ ${ }^{a}$ Escola Superior de Tecnologia e Gestão, Instituto Politécnico de Bragança, 5301-857 Bragança, Portugal \\ ${ }^{\mathrm{b}}$ Univ. Texas San Antonio, Dept. Chem., San Antonio, TX 78249, USA

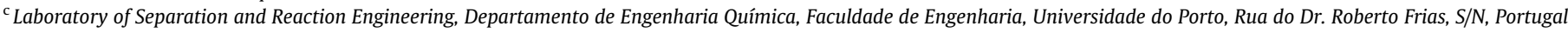

\section{A R T I C L E I N F O}

\section{Article history:}

Received 13 December 2011

Received in revised form 19 January 2012

Accepted 20 January 2012

Available online 6 February 2012

\section{Keywords:}

Metal-organic framework

Xylene isomers

Adsorption equilibrium

Dual-Site Langmuir model

Isosteric heat of sorption

\begin{abstract}
A B S T R A C T
Single and multicomponent adsorption equilibria of xylene isomers: o-xylene (o-x), m-xylene (m-x), pxylene ( $\mathrm{p}-\mathrm{x})$ and ethylbenzene $(\mathrm{eb})$ was investigated on the three dimensional microporous metal-organic framework $\mathrm{Zn}(\mathrm{BDC})(\mathrm{Dabco})_{0.5}(\mathrm{BDC}=1,4$-benzenedicarboxylate, Dabco = 1,4-diazabicyclo[2.2.2]-octane), MOF 1, in the range of temperatures between 398 and $448 \mathrm{~K}$ and partial pressures up to 0.1 bar. The equilibrium data show that a significant amount (around $34 \mathrm{~g} / 100 \mathrm{~g}_{\text {ads }}$ at $398 \mathrm{~K}$ ) of xylene isomers can be adsorbed in MOF 1 . The affinity to the adsorbent measured by the Henry's constants to decreases in the order $0-x>m-x>e b>p-x$ for all temperatures. The zero coverage adsorption enthalpies are all similar and range from 77.4 (eb) to $79.8 \mathrm{~kJ} / \mathrm{mol}(\mathrm{o}-\mathrm{x})$. The Dual-Site Langmuir model (DSL) was used for the interpretation and correlation of the experimental data. The parameters obtained from the pure component isotherms fitting were also used to predict the multicomponent equilibrium data by an extended DSL model. A good agreement was obtained between the predictions and the experimental data. It was also demonstrated that the DSL model is also capable to explain the increase in the isosteric heat of sorption with increasing coverage.
\end{abstract}

(c) 2012 Elsevier Inc. All rights reserved.

\section{Introduction}

The benzene homologs of general formula $\mathrm{C}_{8} \mathrm{H}_{10}$ are generally known as mixed xylenes. The mixture of isomers mainly consists of the three isomeric dimethylbenzenes (ortho-, meta-, and paraxylene) and ethylbenzene. The feedstocks used for xylene production give rise to a mixture containing the four isomers [1].

Para-xylene has by far the largest market of the three isomers. $\mathrm{p}-\mathrm{x}$ is mainly oxidized to terephthalic acid, which can be esterified to dimethyl terephthalate (precursor for polyesters). $0-x$ is oxidized to phthalic anhydride (precursor for plasticizers) and $\mathrm{m}-\mathrm{x}$ to isophthalic acid (precursor for polyesters). EB is dehydrogenated to styrene, which is converted to polystyrene and other polymers $[1,2]$.

These isomers boil so closely together that separating them by conventional distillation is not feasible [2]. Actually, the separation of high-purity p-x from a mixture of mixed xylenes is industrially performed by three main processes: crystallization, adsorption, and a hybrid crystallization/adsorption process [3]. However, about $60 \%$ of the $\mathrm{p}-\mathrm{x}$ produced worldwide is by adsorption technology.

* Corresponding authors. Address: Campus de Santa Apolónia, Apartado 134, 5301-857 Bragança, Portugal. Tel.: +351 273303 125; fax: +351 273313051.

E-mail address: jsilva@ipb.pt (J.A.C. Silva).
Adsorption processes are operated using Simulated Moving Bed technology (SMB), which allows a continuous separation, using zeolites exchanged with cations such as $\mathrm{Na}^{+}, \mathrm{K}^{+}, \mathrm{Ba}^{2+}[2,4-11]$. This process is being studied and simulated in order to provide tools for process understanding, operations and optimization [3,9,12-16]. Those authors have also investigated a Simulated Moving Bed Reactor (SMBR) applied for $p$-xylene production, combining xylene isomerization and selective adsorption operating in liquid phase $[17,18]$.

Porous metal-organic frameworks (MOFs) are crystalline microporous materials and consists of small metal-containing clusters connected three dimensionally by organic ligands. Contrasting to zeolites, which have pores confined by tetrahedral oxide skeletons, the pores within MOFs can be systematically varied by the judicious choice of the metal-containing and/or organic ligands [19]. Due to their unusual features, MOFs are considered promising materials for gas storage, adsorption separations and catalysis [20-32].

Despite the large interest in xylene separations and the potential of MOFs for adsorption separations, experimental data about xylene separation using MOFs are almost inexistent. The few studies found in the literature show promising results. Alaerts et al. [33] demonstrates the first successful use of MOF as selective adsorbent for this difficult task. Vapor-phase experiments carried out by Finsy et al., showed that the selectivity of MIL-47 increases 


\section{Nomenclature}

$b \quad$ Langmuir constant or adsorption affinity constant, $\mathrm{Pa}^{-1}$ $b_{0} \quad$ frequency factor of the affinity constant, $\mathrm{Pa}^{-1}$

$\Delta H \quad$ heat of adsorption, $\mathrm{kJ} / \mathrm{mol}$

$\Delta H_{s t} \quad$ isosteric heat of sorption, $\mathrm{kJ} / \mathrm{mol}$

$n \quad$ number of active sites of adsorption, dimensionless

$q \quad$ amount adsorbed, $\mathrm{p}$ is the pressure of sorbate, $\mathrm{g} / 100 \mathrm{~g}_{\text {ads }}$
$q_{S}$ total number of measurements, dimensionless ideal gas constant, $\mathrm{Pa} \mathrm{m}^{3} \mathrm{~mol}^{-1} \mathrm{~K}^{-1}$ temperature, $\mathrm{K}$ with the degree of pore filling, due to efficient packing effects [34]. Alaerts et al. have investigated MIL-53 and found that this MOF is ortho-selective [35]. Ramesh et al. [36], have carried out effectively the separation of $\mathrm{o}-\mathrm{x} / \mathrm{p}-\mathrm{x}$ mixture using the hydrotropy technique. This technique is used to separate near boiling point isomeric/nonisomeric mixtures and its possible mechanism of separation effect of hydrotropes may be due to the formation of organized aggregates of hydrotrope molecules at a critical concentration.

Recently, Nicolau et al. [37] have shown that the separation of 0 -x from the other $C_{8}$ components in $\mathrm{Zn}(1,4-\mathrm{BDC})(\mathrm{Dabco})_{0.5} \mathrm{MOF}$, denoted as MOF 1, is quite efficient. "BDC" denotes 1,4-benzenedicarboxylate and "Dabco" denotes 1,4-diazabicyclo[2.2.2]-octane. For the adsorbates in this study, the structure of MOF $\mathbf{1}$ is in effect a one-dimensional channel system, despite the three dimensional structure, and is thermally stable. Dubbeldam et al. have reported that MOF 1 presents two energetically different sites of adsorption [38].

This work focuses on the experimental and modeling of the single and multicomponent adsorption equilibrium data of $\mathrm{C}_{8}$ isomers in MOF 1 structure. The pure component experimental data was fitted with the Dual-Site Langmuir model (DSL), and then the model was extended to predict the multicomponent sorption data. Thereafter, the DSL model was used to predict the variation of isosteric heat of sorption with the coverage.

\section{Experimental section}

\subsection{MOF 1 structure}

As revealed in the X-ray single-crystal structure by Kim et al., MOF 1 is constructed of paddle-wheel $\mathrm{Zn}_{2}(\mathrm{COO})_{4}$ clusters bridged by BDC dianions and Dabco pillar linkers to form a three-dimensional framework of a primitive cubic $(\alpha-\mathrm{Po})$ net. There exist two types of intersecting channels of about $7.5 \times 7.5 \AA$ along the $a$-axis and channels of $3.8 \times 4.7 \AA$ along $b$ and $c$ axes, respectively (Fig. 1) [39].

Due to the large kinetic diameters of the adsorbates (see Table 1), it is expected that they can go only through the large channels of $7.5 \times 7.5 \AA$ along $a$-axis. MOF 1 was synthesized according to the procedure described by Kim et al. The information about experimental setup and procedure is reported elsewhere [40,41].

\subsection{Xylene isomers structure}

Fig. 2 shows an approximate three dimensional structure of xylene isomers. From the view along the [100] axis it can be clearly seen that their molecular structure is very similar. The difference lies in where the two methyl groups are attached to the benzenic ring. Counting the carbons atoms from one of the ring carbons bonded to a methyl group, and counting towards the second ring carbon bonded to a methyl group, the o-isomer has the IUPAC name of 1,2-dimethylbenzene, the $m$-isomer has the name of 1,3dimethylbenzene, and the $p$-isomer has the name of 1,4-dimethylbenzene. $e b$ has one ethyl group attached to the benzenic ring. All the $C_{8}$ alkylaromatics used in this work were of analytical grade purchased from Sigma-Aldrich.

\subsection{Adsorption equilibrium apparatus}

The experimental data was obtained in an apparatus developed at the LSRE for the measurement of single and multicomponent breakthrough curves consisting of three main sections. The preparation section includes a syringe pump used to introduce the adsorbable species in the carrier gas followed by a heating chamber where this stream is completely vaporized. The adsorption section consists of a stainless steel column $\left(L=100 \mathrm{~mm}, d_{i}=4.6 \mathrm{~mm}\right)$ packed with MOF 1, placed in a ventilated chromatographic oven, as well as a heated 10 loops sample collector, to collect samples at the outlet of the column. The third part is an analytical section composed by a chromatographic column and a flame ionization detector (FID).

The adsorption column was operated by introducing continuously a known composition of hydrocarbons in a helium stream of minimum purity 99.999\% (ALPHAGAZ 1, Air Liquide, France). A flame ionization detector measures the concentration history at the outlet of the packed bed. During the multicomponent experiments, a $100 \mu$ l-loop collector is used to trap samples from the effluent of the column. After the saturation is reached, the composition of the collected samples is evaluated by chromatography using a $2 \mathrm{~m}$ long, $2 \mathrm{~mm}$ ID, Chromosorb W-HP packed column $5 \%$ Bentone 34, 5\% SP-1200 on Chromosorb 100/120 mesh (Restek Corporation, Bellefonte, PA, USA). Complete information about the experimental apparatus and operating procedure is reported elsewhere $[40,41]$.

\section{Modeling adsorption equilibrium}

For the development of an adsorptive process, it is essential to obtain a good analytical description of the experimental sorption data. Dubbeldam et al. [38] have reported using grand canonical Monte Carlo simulations (GCMC), that MOF 1 presents two energetically different sites of adsorption. At low loading, the bulkier molecules adsorb along the $7.5 \times 7.5 \AA 1 \mathrm{D}$ channels, preferentially near the "boxes" formed by the "BDC" ligands. At high loadings, they adsorb within those "boxes". Therefore, to model equilibrium sorption data we decided to make use of the DSL model, which distinguishes two categories of sorption sites, each one following a Langmuir behavior, reflecting in this way the heterogeneity of the adsorbent. This model was used successfully to predict pure component data of several alkanes in zeolites [42-45]. The adsorption isotherm is

$q(p, T)=q_{A}+q_{B}=q_{S}^{A} \frac{b^{A}(T) p}{1+b^{A}(T) p}+q_{S}^{A} \frac{b^{B}(T) p}{1+b^{B}(T) p}$

where $q$ is the amount adsorbed, $p$ is the pressure of sorbate, $b$ and $q_{S}$ are the adsorption affinity constant (Langmuir constant) and the 


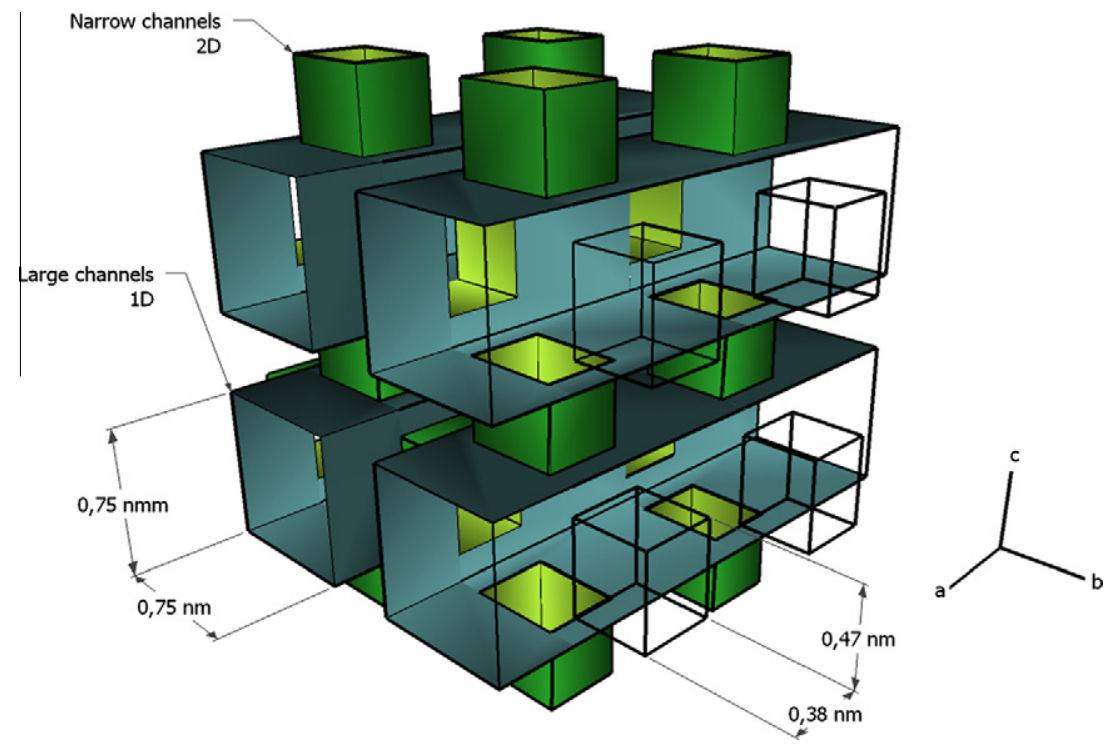

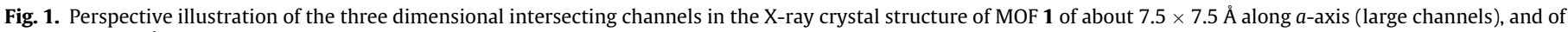
about $3.8 \times 4.7 \AA$ along $b$ and $c$ axes.

Table 1

Kinetic diameters and dipole moment of xylene isomers.

\begin{tabular}{lllll}
\hline Compound & $\mathrm{o}-\mathrm{x}$ & $\mathrm{m}-\mathrm{x}$ & $\mathrm{p}-\mathrm{x}$ & $\mathrm{eb}$ \\
\hline Kinetic diameter, $d_{p}(\AA)[41]$ & 7.4 & 7.1 & 6.7 & 6.7 \\
Dipole moment $(\mathrm{D})$ & 0.62 & 0.36 & 0 & 0.58 \\
\hline
\end{tabular}

saturation capacity of each type of sites, respectively. Here, the superscripts $A$ and $B$ indicate the two type sites of sorption.

The adsorption affinity constant, $b$, is assumed to vary with temperature in sites $A$ and $B$, according to the following equation

$b=b_{0} \exp \left(\frac{-\Delta H}{R T}\right)$

where $b_{0}$ is the frequency factor of the affinity constant, $(-\Delta H)$ is the heat of adsorption, $R$ is the ideal gas constant, and $T$ is the temperature.

The DSL model parameters for the four pure $C_{8}$ alkylaromatics gases on MOF 1 were determined numerically by an optimization procedure. It was assumed that the total saturation loading (the sum of the saturation loading of the two sites) is constant and equal for all isomers, reducing in this way the number of restrictions and the degrees of freedom in the numerical procedure. The mean absolute deviations, $\overline{\Delta q}$, between the predicted, $q$, and the experimental, $q_{\text {exp }}$, values are calculated with

$$
\overline{\Delta q}=\sqrt{\frac{1}{N} \sum_{i=1}^{N}\left(q_{\exp , i}-q_{i}\right)^{2}}
$$

where $N$ is the total number of measurements.

\section{Results and discussion}

\subsection{Pure component isotherms}

The first step in the characterization of an adsorbent for a particular separation is the measurement of the pure component sorption equilibrium. Fig. 3 shows the experimental pure component adsorption isotherms of the $C_{8}$ alkylaromatics at 398, 423 and $448 \mathrm{~K}$ plotted in terms of the loading in $\mathrm{g} / 100 \mathrm{~g}_{\text {ads }}$ as a function of the partial pressure (bar). It can be seen that all isotherms are of type I according to the IUPAC classification. Fig. 3 shows that MOF 1 can adsorb large amounts of $C_{8}$ isomers. Amounts sorbed vary from ca. $35 \mathrm{~g} / 100 \mathrm{~g}_{\text {ads }}$ at $398 \mathrm{~K}$ to ca. $27 \mathrm{~g} / 100 \mathrm{~g}_{\text {ads }}$ at $448 \mathrm{~K}$. These values compare to those found in MOF MIL-47 [34]. It is also found that at the lower temperature of $398 \mathrm{~K}$ the amounts sorbed of all $C_{8}$ isomers is very similar when partial pressure is around 0.1 bar. Thus, the assumption made of the same value of the saturation capacity for all compounds in the fitting procedure seems to be valid.

The lines in Fig. 3 represent the values given by the DSL model. The fitted parameters obtained are reported in Table 2 . We take site $A$ to be the one with higher Langmuir constant, which according to
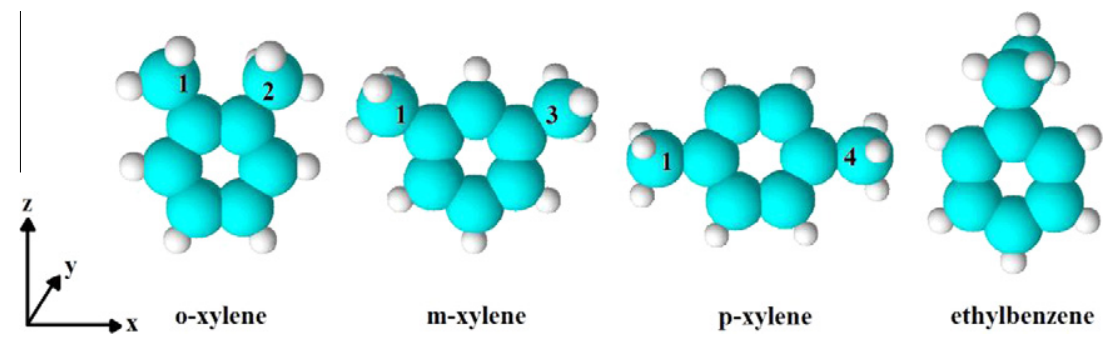

ethylbenzene

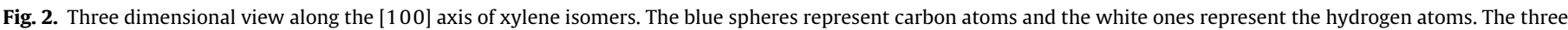

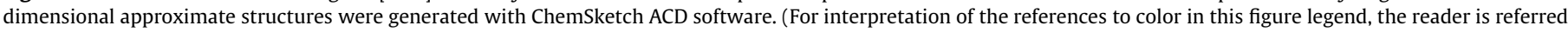
to the web version of this article.) 

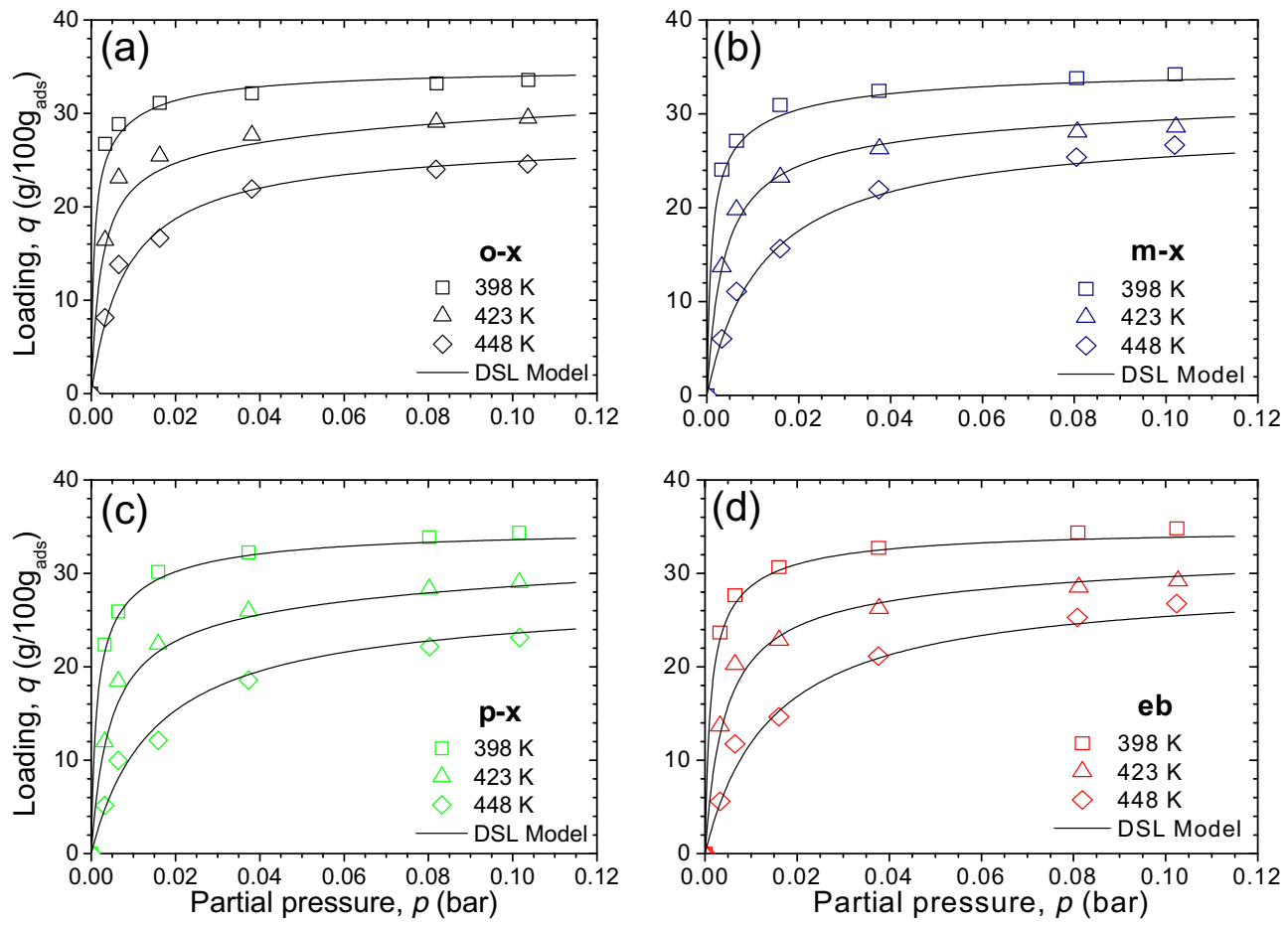

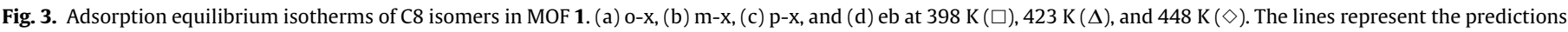
of the DSL model.

Table 2

Dual-Site Langmuir model parameters and deviations between model and experimental measurements.

\begin{tabular}{|c|c|c|c|c|c|}
\hline Parameter & Unit & $0-\mathrm{x}$ & $\mathrm{m}-\mathrm{x}$ & $\mathrm{p}-\mathrm{x}$ & eb \\
\hline$q_{S}^{A}$ & $\mathrm{~g} / 100 \mathrm{~g}_{\mathrm{ads}}$ & 26.2 & 28.10 & 26.45 & 28.68 \\
\hline$q_{S}^{B}$ & $\mathrm{~g} / 100 \mathrm{~g}_{\mathrm{ads}}$ & 8.67 & 6.76 & 8.42 & 6.19 \\
\hline$q_{S}$ & $\mathrm{~g} / 100 \mathrm{~g}_{\mathrm{ads}}$ & 34.87 & 34.87 & 34.87 & 34.87 \\
\hline$-\Delta H_{A}$ & $\mathrm{~kJ} / \mathrm{mol}$ & 79.84 & 77.44 & 78.23 & 77.40 \\
\hline$-\Delta H_{B}$ & $\mathrm{~kJ} / \mathrm{mol}$ & 145.34 & 136.50 & 139.38 & 151.11 \\
\hline \multicolumn{6}{|c|}{ Temperature $=398 \mathrm{~K}$} \\
\hline$H$ & $\mathrm{~g} / \mathrm{gads}_{\text {bar }}$ & 479.77 & 317.73 & 256.58 & 278.41 \\
\hline$b^{A}$ & bar $^{-1}$ & 1796.1 & 1117.2 & 946.31 & 954.33 \\
\hline$b^{B}$ & $\mathrm{bar}^{-1}$ & 105.80 & 55.77 & 75.16 & 75.91 \\
\hline \multicolumn{6}{|c|}{ Temperature $=423 \mathrm{~K}$} \\
\hline$H$ & $\mathrm{~g} / \mathrm{g}_{\text {ads }}$ bar & 113.87 & 79.15 & 62.47 & 69.08 \\
\hline$b^{A}$ & bar $^{-1}$ & 431.98 & 280.45 & 234.23 & 239.74 \\
\hline$b^{B}$ & $\mathrm{bar}^{-1}$ & 7.91 & 4.88 & 6.25 & 5.12 \\
\hline \multicolumn{6}{|c|}{ Temperature $=448 \mathrm{~K}$} \\
\hline$H$ & $\mathrm{~g} / \mathrm{g}_{\text {ads }}$ bar & 31.98 & 23.12 & 17.97 & 20.18 \\
\hline$b^{A}$ & $\mathrm{bar}^{-1}$ & 121.80 & 82.14 & 67.75 & 70.26 \\
\hline$b^{B}$ & bar $^{-1}$ & 0.79 & 0.56 & 0.69 & 0.47 \\
\hline$\sum \Delta q$ & - & 0.22 & 0.18 & 0.19 & 0.17 \\
\hline
\end{tabular}

Dubbeldam et al. [38] represents sorption along the $7.5 \times 7.5 \AA 1 \mathrm{D}$ channels near the "boxes". The lines in Fig. 3 show that the DSL model describes with good accuracy the adsorption isotherms.

The parameters arising from the numerical optimization procedure shown in Table 2 indicate that the heat of sorption of the isomers is very different in type site $A$ and $B$ but very similar for all the compounds in each site, around $78 \mathrm{~kJ} / \mathrm{mol}$ in site $A$ and $140 \mathrm{~kJ} / \mathrm{mol}$ in site $B$. The amounts sorbed of xylene isomers in site $A$ is considerably higher than in site $B$ since the values of parameter $b$ for site $A$ are much higher than for site $B$. This is valid for all the compounds. Table 2 also shows that the affinity to the adsorbent measured by the values of the Henry's constants decrease in the order $0-\mathrm{x}>\mathrm{m}-\mathrm{x}>\mathrm{eb}>\mathrm{p}-\mathrm{x}$ for all temperatures and is similar in both sites $A$ and $B$. Moreover, as the temperature increases the interaction of the isomers with site $B$ decrease significantly and is practically negligible at the temperature of $448 \mathrm{~K}$, as can be concluded by the small values of the Henry and Langmuir constants at this temperature.

\subsubsection{Isosteric heat of sorption}

Data about heats of sorption [46] are essential for the proper design and operation of adsorption processes and can also give insight regarding the validation of sorption isotherm models. In most systems the isosteric heats can be defined by [47],

$\frac{-\Delta H_{s t}}{R T^{2}}=-\left(\frac{\partial \ln p}{\partial T}\right)_{q}$

The variation of the isosteric heat of sorption with loading can be calculated for the DSL model [48]. Taking the total derivative of the DSL Eq. ( 1 , and assuming constant loading $(d q=0)$, we have

$\left(\frac{\partial \ln p}{\partial T}\right)_{q}=\frac{1}{R T^{2}} \frac{q_{S}^{A} \frac{b^{A} \Delta H_{A}}{\left(1+b^{A} p\right)^{2}}+q_{S}^{B} \frac{b^{B} \Delta H_{B}}{\left(1+b^{B} p\right)^{2}}}{q_{S}^{A} \frac{b^{A}}{\left(1+b^{A} p\right)^{2}}+q_{S}^{B} \frac{b^{B}}{\left(1+b^{B} p\right)^{2}}}$

where $\Delta H_{A}$ and $\Delta H_{B}$ is the adsorption enthalpy in site $A$ and $B$, respectively. Thus, combining Eqs. (3) and (4) we obtain the following expression for the isosteric heat of sorption for the DSL model

$\left(-\Delta H_{s t}\right)=\frac{q_{S}^{A} \frac{b^{A} \Delta H_{A}}{\left(1+b^{A} p\right)^{2}}+q_{S}^{B} \frac{b^{B} \Delta H_{B}}{\left(1+b^{B} p\right)^{2}}}{q_{S}^{A} \frac{b^{A}}{\left(1+b^{A} p\right)^{2}}+q_{S}^{B} \frac{b^{B}}{\left(1+b^{B} p\right)^{2}}}$

The above equation shows the variation of the isosteric heat as a function of the amount sorbed by relating the pressure to the amount adsorbed via the DSL Eq. (1). Knowing that the affinity constant $b$ is temperature dependent, the isosteric heat of sorption can be predicted for the three temperatures investigated in this work. 
(a)
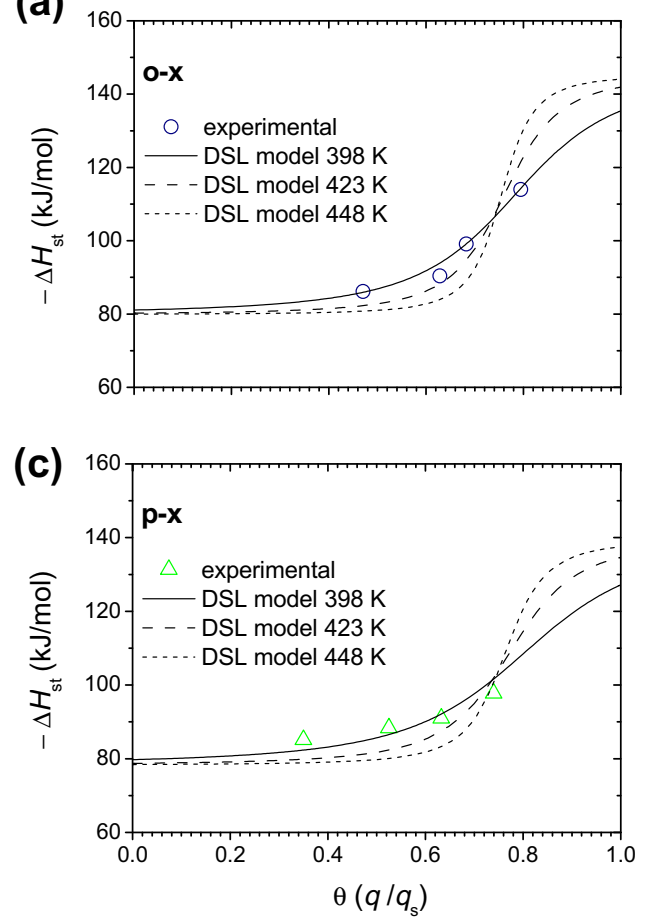

(b)

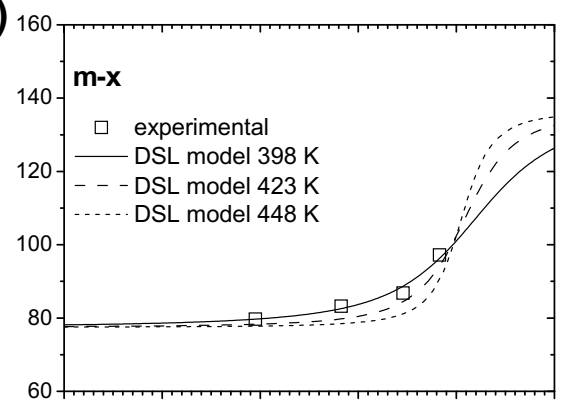

(d)

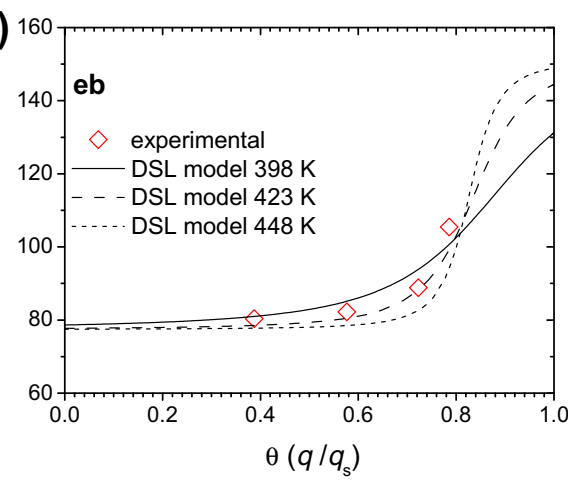

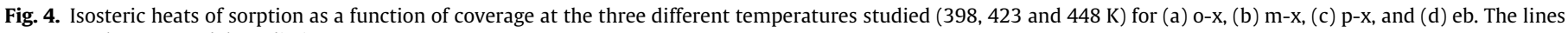
represent the DSL model prediction.

Fig. 4 shows the experimental and numerical isosteric heats of sorption (calculated via Eq. (5)) as a function of coverage. It can be seen that the DSL model is capable to explain reasonably the experimental verification of the rise of the isosteric heat with coverage. Accordingly, this increase is explained by an isosteric heat inflection (intermediate regime) connecting two plateaus one that prevails at low and intermediate coverage (with a lower $\Delta H_{A}$ corresponding to sorption in site $A$ ) and other at high coverage (with a higher $\Delta H_{B}$ corresponding to sorption in site $B$ ).

The evolution of the isosteric heat of sorption versus loading for each site predicted by the DSL model is illustrated in Fig. 5. This representation is easier for a better understanding of the rise of the total isosteric heat with the coverage. At low to intermediate coverage the sorption in site A contribute significantly for the isosteric heat whereas at high coverage the contribution is due to sorption in site $B$. Since the heat release is higher when molecules adsorb in site $B$ (around $140 \mathrm{~kJ} / \mathrm{mol}$, see Table 2 ) we observe an increase of the total isosteric heat of sorption as the system approaches saturation.

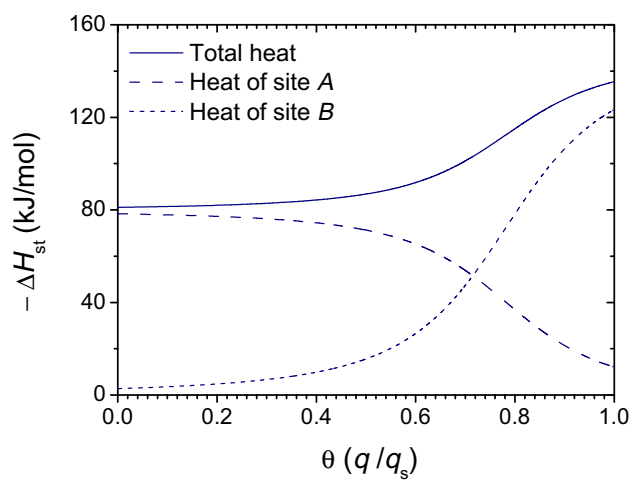

Fig. 5. Isosteric heats of sorption versus fractional loading predicted by the DSL model. Illustration of the evolution of the heat of sorption in sites $A$ and $B$. This example corresponds to the isosteric heats of sorption of o-x at $398 \mathrm{~K}$.

\subsection{Multicomponent adsorption isotherms}

Using the parameters given by the single component adsorption equilibrium fitting, the mixture sorption data can be predicted by an extended DSL isotherm model. As a result, the amount adsorbed of component $i, q_{i}$, in a mixture is given by

$q_{i}(p, T)=q_{S, i}^{A} \frac{b_{i}^{A}(T) p_{i}}{1+\sum_{k=1}^{n} b_{k}^{A}(T) p_{k}}+q_{S, i}^{B} \frac{b_{i}^{B}(T) p_{i}}{1+\sum_{k=1}^{n} b_{k}^{B}(T) p_{k}}$

where $n$ is the number of $C_{8}$ isomers in the mixture.

Fig. 6, shows the multicomponent adsorption equilibrium isotherms fitted by Eq. (6). Together with the operating conditions, the numerical values of the amount adsorbed for each equimolar quaternary breakthrough can also be found in the literature [37]. Fig. 6 demonstrates that $0-x$ is at the temperatures studied the preferential adsorbed component. This is also confirmed by the o-x Henry and affinity constants reported in Table 2. However, as the temperature increases the difference in the amount adsorbed relatively to the other $C_{8}$ alkylaromatics decrease. We also note that the extended DSL model predictions represented by the lines in Fig. 6 give a reasonable description of the quaternary adsorption data, which is also corroborated by the mean absolute deviations between the predicted and the experimental data in Table 3 .

Fig. 7 shows the selectivity's calculated by the ratio of $0-x$ relatively to the other isomers as a function of total mixture loading for the quaternary experiments reported in Fig. 6 . The highest selectivity if relatively to $\mathrm{p}-\mathrm{x}(\approx 1.83)$ followed by e-b $(\approx 1.65)$ and $\mathrm{m}-\mathrm{x}$ $(\approx 1.43)$ at the temperature of $398 \mathrm{~K}$ (Fig. 7a). The increase of the temperature decreases slightly the selectivity's (Fig. 7b and c). DSL predicts that the selectivity is practically constant for amounts adsorbed lower than $25 \%$ beginning to decreases relatively to $\mathrm{p}-\mathrm{x}$ and increase for the other isomers close to saturation (around $35 \%$ amount adsorbed). Fig. 7 shows that at the temperature of $398 \mathrm{~K}$ the experimental values are in accordance with the DSL model being slightly different at the other temperatures. The values of the selectivity reported here are lower than the ones 
(a)

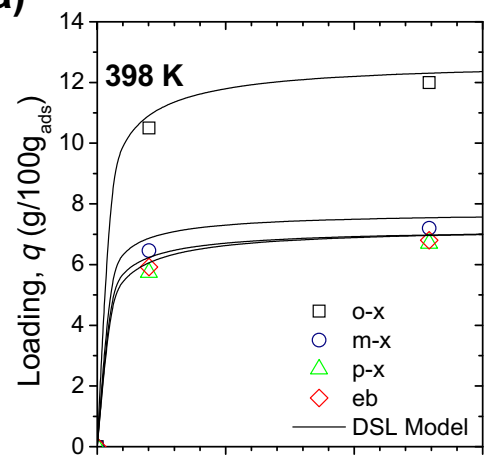

(b)

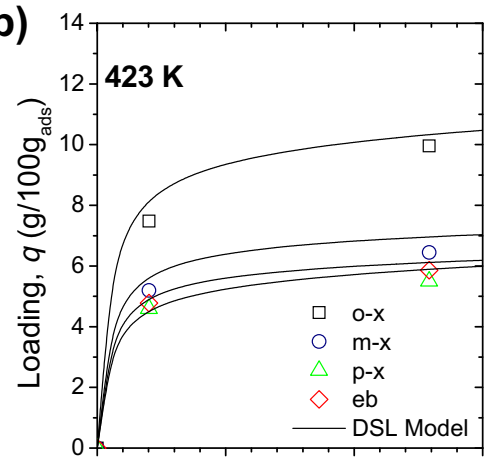

(c)

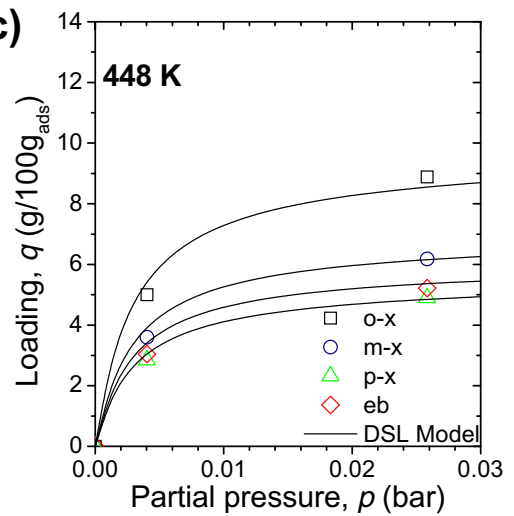

Fig. 6. Quaternary adsorption equilibrium isotherms fitted by the DSL model for an equimolar mixture of o-x/m-x/p-x/eb at (a) 398, (b) 423 , and $448 \mathrm{~K}$ (c)

Table 3

Mean absolute deviations between predicted (extended DSL) and measured data, for quaternary adsorption equilibrium on MOF 1.

\begin{tabular}{lllll}
\hline & $\overline{\Delta q}_{398}$ & $\overline{\Delta q}_{423}$ & $\overline{\Delta q}_{448}$ & $\sum \Delta q$ \\
\hline Equimolar quaternary mixture & 0.12 & 0.14 & 0.10 & 0.36 \\
\hline
\end{tabular}

reported by Finsy et al. [34] for MOF MIL-47 where it can reach 2 for $\mathrm{p}-\mathrm{x} / \mathrm{m}-\mathrm{x}$ and 3.4 for $\mathrm{p}-\mathrm{x} / \mathrm{eb}$. However, MOF 1 has the main feature of being ortho-selective.

Without a detailed molecular simulation study we can rationalize the selectivity of xylene isomers observed in Fig. 7 in terms of the dipole moment of the isomers. Table 1 shows that $0-x$ has the highest dipole moment $(0.62 \mathrm{D})$ followed by $\mathrm{m}-\mathrm{x}(0.36 \mathrm{D})$ and $\mathrm{p}-\mathrm{x}$ (0). For eb the dipole moment is $0.58 \mathrm{D}$ but since the molecular structure is different a balance including surface area should be made. Accordingly, the zero value of the dipole moment of $\mathrm{p}-\mathrm{x}$ probably dictates why it is the more weakly adsorbed component in the competition for sorption in MOF 1.
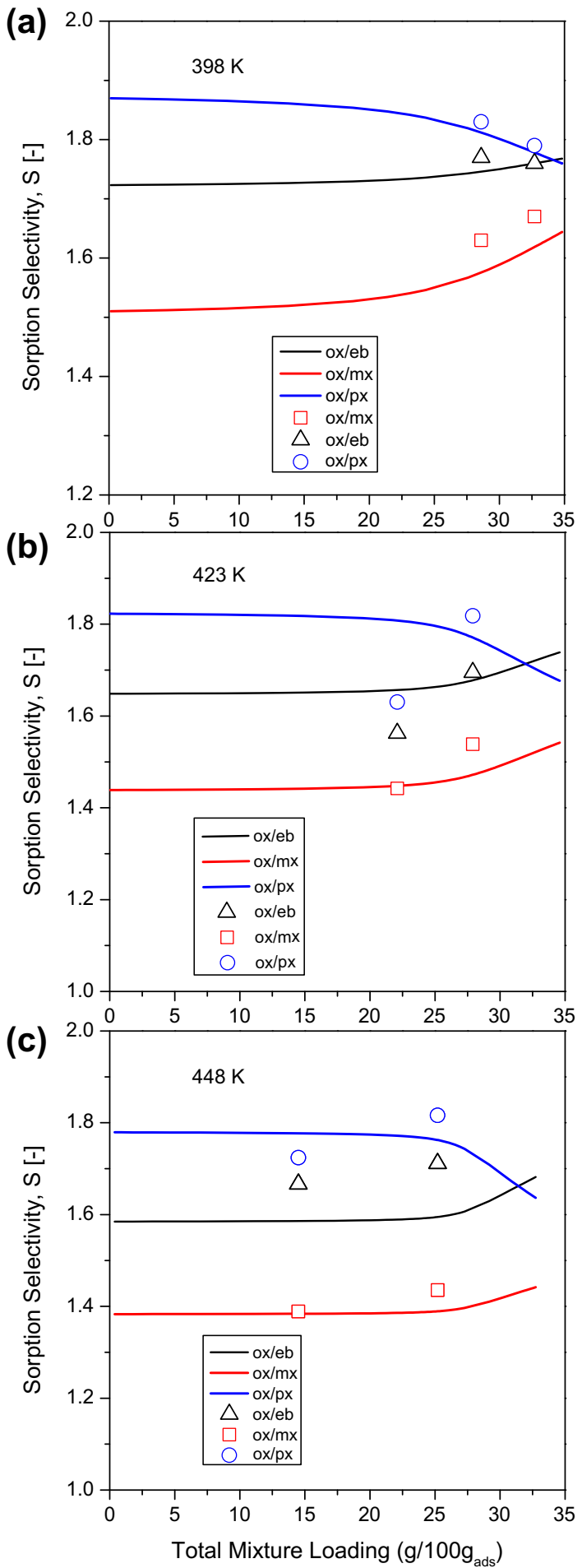

Fig. 7. Effect of temperature in the sorption selectivity as a function of total mixture loading for an equimolar quaternary mixture of $0-x / m-x / p-x / e b$ at (a) 398, (b) 423, and $448 \mathrm{~K}(\mathrm{c})$. Points are experimental data and lines DSL model predictions.

\section{Conclusions}

An investigation of the adsorption equilibria of xylene isomers in MOF 1 was performed at temperatures ranging from 398 to $448 \mathrm{~K}$ and total hydrocarbon pressures up to 0.10 bar.

The equilibrium data clearly show that a significant amount of xylene isomers can be adsorbed in MOF 1. At high pressure, the 
adsorption capacity for all the components varies from $35 \mathrm{~g} / 100 \mathrm{~g}_{\text {ads }}$ and $26 \mathrm{~g} / 100 \mathrm{~g}_{\text {ads }}$ at 398 and $448 \mathrm{~K}$, respectively. The affinity to the adsorbent measured by the values of the Henry's constants, decrease in the order $0-x>m-x>e b>p-x$ for all temperatures. The zero coverage adsorption enthalpies are all similar and range from 77.4 (eb) to $79.8 \mathrm{~kJ} / \mathrm{mol}(\mathrm{o}-\mathrm{x})$.

It was used a DSL model to correlate the equilibrium data, in order to taking into account the heterogeneity caused by the presence of two different sites of adsorption. The parameters of the model were obtained from the fitting of the pure component isotherms of the four xylene isomers studied. After that, the DSL model was extended to predict the quaternary adsorption equilibria and the results were compared with the experiments. A good agreement was obtained between the predictions of the DSL model and the experimental data.

The combination of the DSL model together with the definition of the isosteric heat resulted in an equation that was used to represent the isosteric heat of sorption as a function of the uptake. The validity of the DSL model was confirmed once again by the good prediction of the experimental evolution of the isosteric heat with the coverage. It was discovered that the rise of the isosteric with coverage for this system can be explained by the presence of two different energetic sites $A$ and $B$ in the MOF. This result indicates that the calculation of the experimental isosteric heats of sorption as a function of coverage can be a valuable tool to justify an isotherm model.

Moreover, the results arising from this work indicate that MOF 1 can be a promising adsorbent to separate 0 -x from the other $C_{8}$ components.

\section{Acknowledgments}

José A.C. Silva acknowledges the financial support from Fundação para a Ciência e Tecnologia under Project POCI/EQU/ 60828/2004. Patrick S. Bárcia acknowledges a FCT PhD Grant (SFRH/BD/30994/2006). This work was supported by an Award CHE 0718281 from the NSF (BC).

\section{References}

[1] J. Fabri, U. Graeser, T. Simo, Ullmann's Encyclopedia of Industrial Chemistry, sixth ed., Wiley-VCH, Weinheim, Germany, 2002 (electronic release).

[2] J.J. Jeanneret, A.R. Meyers, Handbook of Petroleum Refining Processes, McGraw-Hill, New York, 1997.

[3] M. Minceva, A.E. Rodrigues, AIChE Journal 53 (2007) 138-149.

[4] D.B. Broughton, C.G. Gerhold, Continuous Sorption Process Employing Fixed Bed of Sorbent and Moving Inlets and Outlets, US Patent 2985 589, 1961

[5] D.B. Broughton, R.W. Neuzil, J.M. Pharis, C.S. Brearley, Chemical Engineering Progress 66 (1970) 70-75.

[6] V. Cottier, J.P. Bellat, M.H. Simonot-Grange, A. Methivier, Journal of Physical Chemistry B 101 (1997) 4798-4802.

[7] M. Goddard, D.M. Ruthven, Zeolites 6 (1986) 283-289.

[8] R.E. Hulme, R.E. Rosensweig, D.M. Ruthven, Industrial \& Engineering Chemistry Research 30 (1991) 752-760.

[9] A.E. Rodrigues, M. Minceva, UOP's Parex: Modeling, Simulation and Optimization, Enpromer, Brasil, 2005.

[10] D.M. Ruthven, Principles of Adsorption and Adsorption Processes, John Wiley \& Sons, New York, 1984.

[11] D.M. Ruthven, M. Goddard, Zeolites 6 (1986) 275-282.

[12] P.S. Gomes, M. Minceva, A.E. Rodrigues, Separation Science and Technology 43 (2008) 1974-2002
[13] M. Minceva, A.E. Rodrigues, Industrial \& Engineering Chemistry Research 41 (2002) 3454-3461.

[14] M. Minceva, A.E. Rodrigues, Separation Science and Technology 38 (2003) 1463-1497.

[15] M. Minceva, A.E. Rodrigues, Computers \& Chemical Engineering 29 (2005) 2215-2228.

[16] P.S. Gomes, M. Minceva, A.E. Rodrigues, Separation Science and Technology 42 (2007) 3555-3591.

[17] M. Minceva, P.S. Gomes, V. Meshko, A.E. Rodrigues, Chemical Engineering Journal 140 (2008) 305-323.

[18] G. Bergeot, D. Leinekugel-Le-Cocq, L. Wolff, L. Muhr, M. Bailly, Oil \& Gas Science and Technology - Revue IFP Energies Nouvelles 65 (5) (2010) 721733.

[19] J.L. Rowsell, O.M. Yaghi, Microporous and Mesoporous Materials 73 (2004) 3 14.

[20] B.L. Chen, C.D. Liang, J. Yang, D.S. Contreras, Y.L. Clancy, E.B. Lobkovsky, O.M Yaghi, S. Dai, Angewandte Chemie, International Edition 45 (2006) 1390-1393.

[21] B.L. Chen, S.Q. Ma, F. Zapata, F.R. Fronczek, E.B. Lobkovsky, H.C. Zhou, Inorganic Chemistry 46 (2007) 1233-1236.

[22] B.L. Chen, N.W. Ockwig, A.R. Millward, D.S. Contreras, O.M. Yaghi, Angewandte Chemie, International Edition 44 (2005) 4745-4749.

[23] B.L. Chen, Y. Yang, F. Zapata, G.N. Lin, G.D. Qian, E.B. Lobkovsky, Advanced Materials 19 (2007) 1693-1696.

[24] G. Ferey, C. Mellot-Draznieks, C. Serre, F. Millange, Accounts of Chemica Research 38 (2005) 217-225.

[25] C. Janiak, Dalton Transactions (2003) 2781-2804

[26] B. Kesanli, W.B. Lin, Coordination Chemistry Reviews 246 (2003) 305-326.

[27] S. Kitagawa, R. Kitaura, S. Noro, Angewandte Chemie, International Edition 43 (2004) 2334-2375.

[28] W.B. Lin, Journal of Solid State Chemistry 178 (2005) 2486-2490.

[29] S.Q. Ma, D.F. Sun, X.S. Wang, H.C. Zhou, Angewandte Chemie, International Edition 46 (2007) 2458-2462.

[30] T.K. Maji, R. Matsuda, S. Kitagawa, Nature Materials 6 (2007) 142-148.

[31] L. Pan, D.H. Olson, L.R. Ciemnolonski, R. Heddy, J. Li, Angewandte Chemie International Edition 45 (2006) 616-619.

[32] T.J. Taylor, V.L. Bakhmutov, F.P. Gabbai, Angewandte Chemie, International Edition 45 (2006) 7030-7033.

[33] L. Alaerts, C.E.A. Kirschhock, M. Maes, M.A. van der Veen, V. Finsy, A. Depla, J.A. Martens, V.G. Baron, P.A. Jacobs, J.E.M. Denayer, D.E. De Vos, Angewandte Chemie, International Edition 46 (2007) 4293-4297.

[34] V. Finsy, H. Verelst, L. Alaerts, D. De Vos, P.A. Jacobs, G.V. Baron, J.F.M. Denayer Journal of the American Chemical Society 130 (2008) 7110-7118.

[35] L. Alaerts, M. Maes, L. Giebeler, P.A. Jacobs, J.A. Martens, J.F.M. Denayer, C.E.A Kirschhock, D. De Vos, Journal of the American Chemical Society 130 (2008) 14170-14178

[36] N. Ramesh, C. Jayakumar, N.N. Gandhi, Chemical Engineering \& Technology 32 (2009) 129-133.

[37] M.P.M. Nicolau, P.S. Bárcia, J.A.C. Silva, B.L. Chen, A.E. Rodrigues, Journal of Physical Chemistry B 113 (2009) 13173-13179.

[38] D. Dubbeldam, C.J. Galvin, K.S. Walton, D.E. Ellis, R. Snurr, Journal of the American Chemical Society 130 (2008) 10884-10885.

[39] D.N. Dybtsev, H. Chun, K. Kim, Angewandte Chemie, International Edition 43 (2004) 5033-5036.

[40] P.S. Barcia, J.A.C. Silva, A.E. Rodrigues, Industrial \& Engineering Chemistry Research 45 (2006) 4316-4328.

[41] P.S. Barcia, F. Zapata, J.A.C. Silva, A.E. Rodrigues, B.L. Chen, Journal of Physica Chemistry B 111 (2007) 6101-6103.

[42] J.X. Liu, M. Dong, Z.L. Sun, Z.F. Qin, J.G. Wang, Colloids and Surfaces A 247 (2004) 41-45.

[43] P.S. Barcia, J.A.C. Silva, A.E. Rodrigues, Microporous and Mesoporous Materials 79 (2005) 145-163.

[44] R. Krishna, R. Baur, Separation and Purification Technology 33 (2003) 213-254

[45] B. Smit, R. Krishna, Molecular simulations in zeolitic process design, in: 17th International Symposium on Chemical Reaction Engineering: Challenges and Opportunities in a Global Environment (ISCRE 17), Hong Kong Peoples R China, 2002.

[46] S. Sircar, D.V. Cao, Chemical Engineering \& Technology 25 (2002) 945-949.

[47] R.M. Barrer, Zeolites and Clay Minerals as Sorbents and Molecular Sieves, Academic Press, London, 1978.

[48] D.D. Do, Adsorption Analysis: Equilibria and Kinetics, Imperial College Press, London, 1998. 